front one-fourth width of head, of equal width, frontal bristles stronger, two orbital bristles directed strongly forward; third antennal joint not so narrowed, palpi and labella more yellow. Macrochaetae of abdomen more differentiated from the macrochaeta- like bristles, which latter are very much weaker; claws and pulvilli only a little elongate. Abdomen less conical and nearly as wide as thorax.

Length of body, nearly $7 \mathrm{~mm}$.; of wing, $6 \mathrm{~mm}$.

\title{
THE EARLY STAGES OF NERICE BIDENTATA.
}

\section{BY CAROLINE G. SOULE, BROOKLINE, MASS.}

The egg, found on the under side of an elm leaf, Aug. 9, I891, was hemispherical, the flat side being attached to the leaf. It was greenish yellow with a whitish bloom over it, and was very like the egg of Nadata gibbosa. It hatched on Aug. 13th.

The young larva was $\frac{3}{16}$ inch long, of a deep green color, and with sparse hairs. Head brown, lighter on the median suture. The fifth segment had a dorsal and substigmatal spot of shining brown, and the IIth segment had a dorsal spot of the same color. The feet and props were shining brown in color. Anal props were very slender and were raised when the larva walked. The body, at rest, was arched between the feet and abdominal props, and between the abdominal and anal props.

Aug. I6. Ist moult. Length $\frac{1}{4}$ inch. Head large, almost round, bilobed, pale olive green with dark green face-lines. Body pale glassy green, darker on the dorsum. The glassy effect was striking. 5th segment had a large brown double tubercle on the dorsum, and a substigmatal, smaller one on each side. The tenth segment had a substigmatal brown patch on each side, and the IIth a brown single tubercle or hump, on the dorsal line. Feet brown. Anal props striped with brown; abdominal props brown. Very short, sparse hairs all over the body. Head very smooth. Body arched when at rest, as before.

Aug. 20. 2nd moult. $\frac{3}{8}$ inch long. Head much larger than xst segment, clear green, glassy, with brown face-lines. Body glassy green, translucent, with very few hairs; a faint white lateral line, and a brown, broken substigmatal line appeared; the brown substigmatal patches on $5^{\text {th }}$ and roth segments were as before. $5^{\text {th }}$ segment had a large double hump, tipped with brown, I Ith had the large single hump as before; $4^{\text {th }}$ and 6th had each a double wart on dorsum. Feet brown and shining. Props pale brown banded with dark brown. Anal props slender. Rested arched as before. Ate the leaf from the edge to the mid-rib at the tip, and rested on the bared mid-rib. Aug. 2I. The marks had grown clearer and each segment from 6th to toth showed a small brown-tipped wart on the dorsal line, and from each wart a white oblique line extended downward and backward, on each side. On the first 3 segments a white subdorsal line appeared. The effect of the dorsal line was that of the edge of a serrate leaf.

Aug. 23. 3d moult. $\frac{8}{8}$ in. long. Head large, round, bilobed, smooth, green with dark face lines. Body green, with a broken, brown substigmatal line edged above with yellow, and a double yellow stigmatal line. First three segments had a double white subdorsal line. 4th segment had a double dorsal hump, tipped with brown; 5 th, a much larger double hump, yellow green, tipped with brown, the brown extending down the front and back like a dorsal line lifted by the hump! 6th to Ioth segments had similar humps, but smaller, like that on 4th. $x$ Ith segment had a large single hump with brown tip. From all these humps extended oblique white patches. Feet green with a dark, vertical line. Props pale brown 
banded with darker brown. Anal props slender, green with a vertical brown stripe. Anal shield shining green like the head. Spiracles, heretofore unnoticeable, green with a brown line on each side, and from them spread white lines like veins, distinct on the green sides of the larva.

Aug. 27. 4th moult. I inch long. Head large, round, smooth, shining green, with a white line on each side of the median suture, and a black line about halfway between this and the edge of head. This black line was edged with whiter on the outer side. Body green. First three segments had, on each side of dorsum, a wide white longitudinal line, below that a narrower one, below that a broken one. The humps were as before except that on IIth segment, which became double. All the humps were unevenly double, the first point being longer than that behind it, as if the second point grew out of the base of the first. The white patches extended up the sides of the humps, and between these patches the green of the body, on the sides, made oblique lines. Sides and venter green. There was a broken substigmatal line of brown edged above with yellow, extending from head to tips of anal props. Feet green with a vertical dark line. Props. green with a brown bar, this bar being crossed by two darker brown lines.

Aug. 30. The brown of the tips of the humps had almost disappeared, as had the substigmatal line. The principal color was semi-opaque white, through which the deep blue-green of the body appeared in lines here and there,-notably the oblique lines on the sides,-and on the venter.

Sept. 3d. The larva was $1 \frac{5}{8}$ inches in length and $\frac{7}{16}$ inch from the venter to the tip of the hump on $5^{\text {th }}$ segment. In the afternoon it grew dull in color, the humps seemed to be retracted, and, the next day, were almost level with the dorsal line, and the larva looked small and moist. It spun a few threads to fasten a leaf to the tin.
Sept. 8th. The pupa appeared. Pupa $\frac{1}{1} \frac{1}{6}$ inch long, neither stout nor slender, dark brown with much darker head, thorax, wing-cases, anal point, and bands between the segments. Eye-cases prominent and very smooth. Segments distinctly ridged on the edges, and pitted between these ridges. Anal point long, slender, sharp. The pupa was very active, rolling a foot or more at a time.

Miscellaneous Notes. - By accident the pages of the last number of Psyche were marked April instead of May.

An interesting sketch of protective resemblance as displayed in the animal world was given in February before the Belgian academy by Dr. Felix Plateau, and will be found in its Bulletins, pp. 89-135. Interesting examples among insects are given.

A new classification of the Acaroidea with full details and an enumeration of the genera is given by Dr. Trouessart in the Revue des sciences naturelles de l'Ouest of Paris for January, I892. Five suborders and ten families are recognized and six of the latter are separated into twenty-four subfamilies.

The eighth part of the leisurely Introduction to entomology by Kolbe has appeared and contains some interesting summaries. The consideration of the muscles is concluded, and the mechanism and physiology of flight and other movements considered with interesting topical bibliographies. The nervous system is then taken up and its main features and especially the brain discussed, followed again by bibliographies.

The extensive but in no way expensive work upon the families and genera of butterflies begun in 1885 by Schatz and continued after his death in 1887 by Röber has just been completed by the publication of the sixth part. The neuration of nearly five hundred different butterflies, representing almost as many genera and accompanied by some rude details of the structure of the legs, palpi, and 

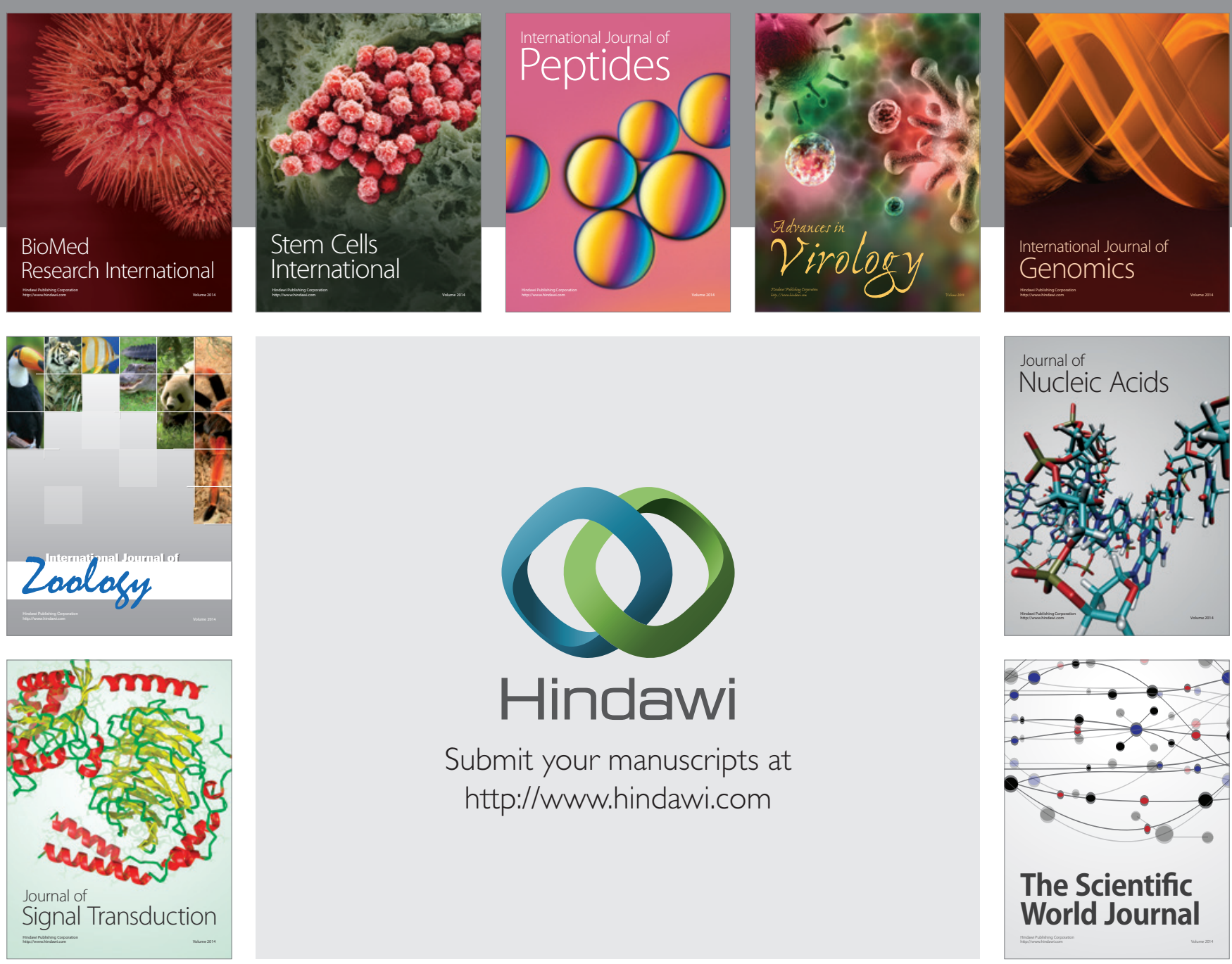

Submit your manuscripts at

http://www.hindawi.com
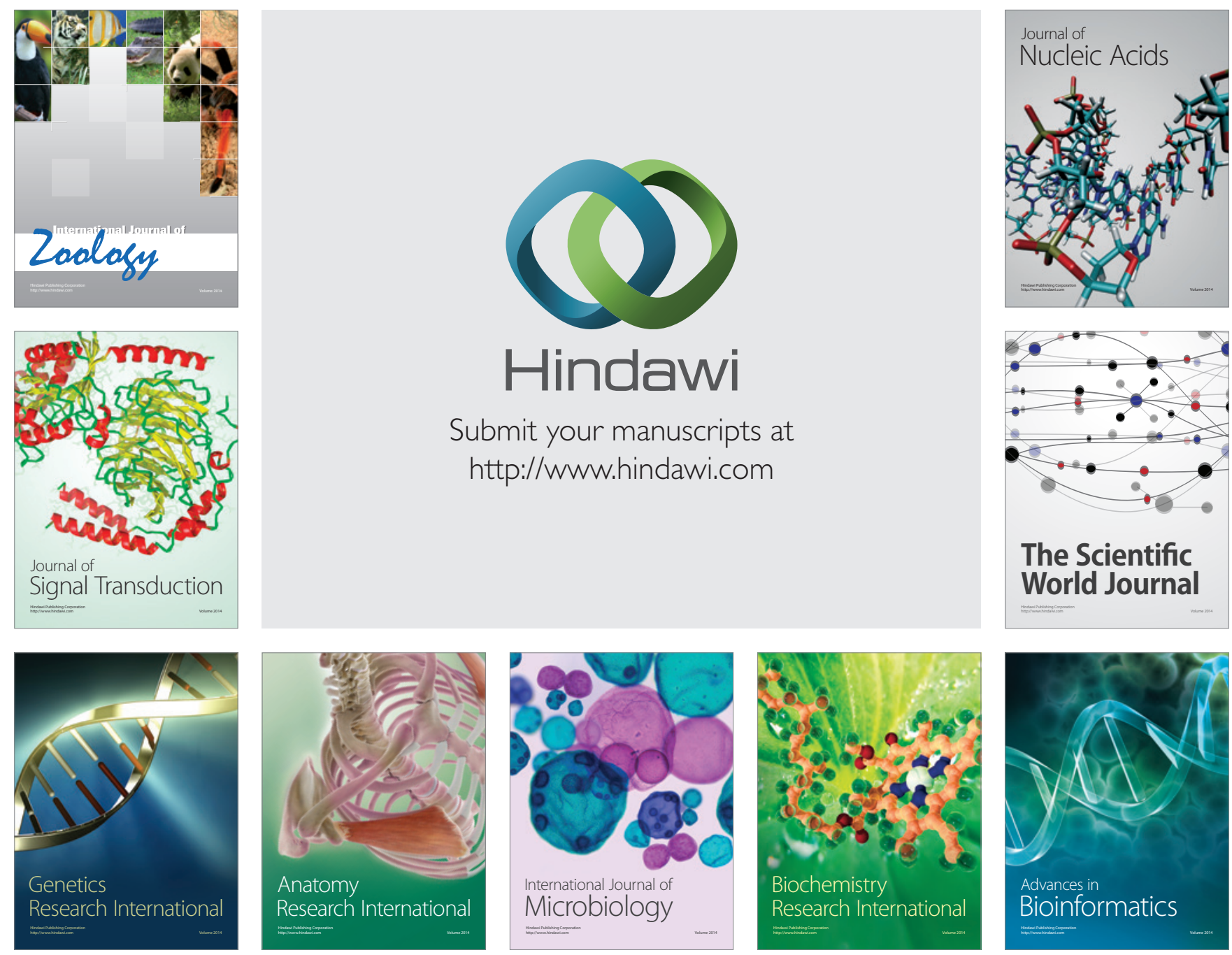

The Scientific World Journal
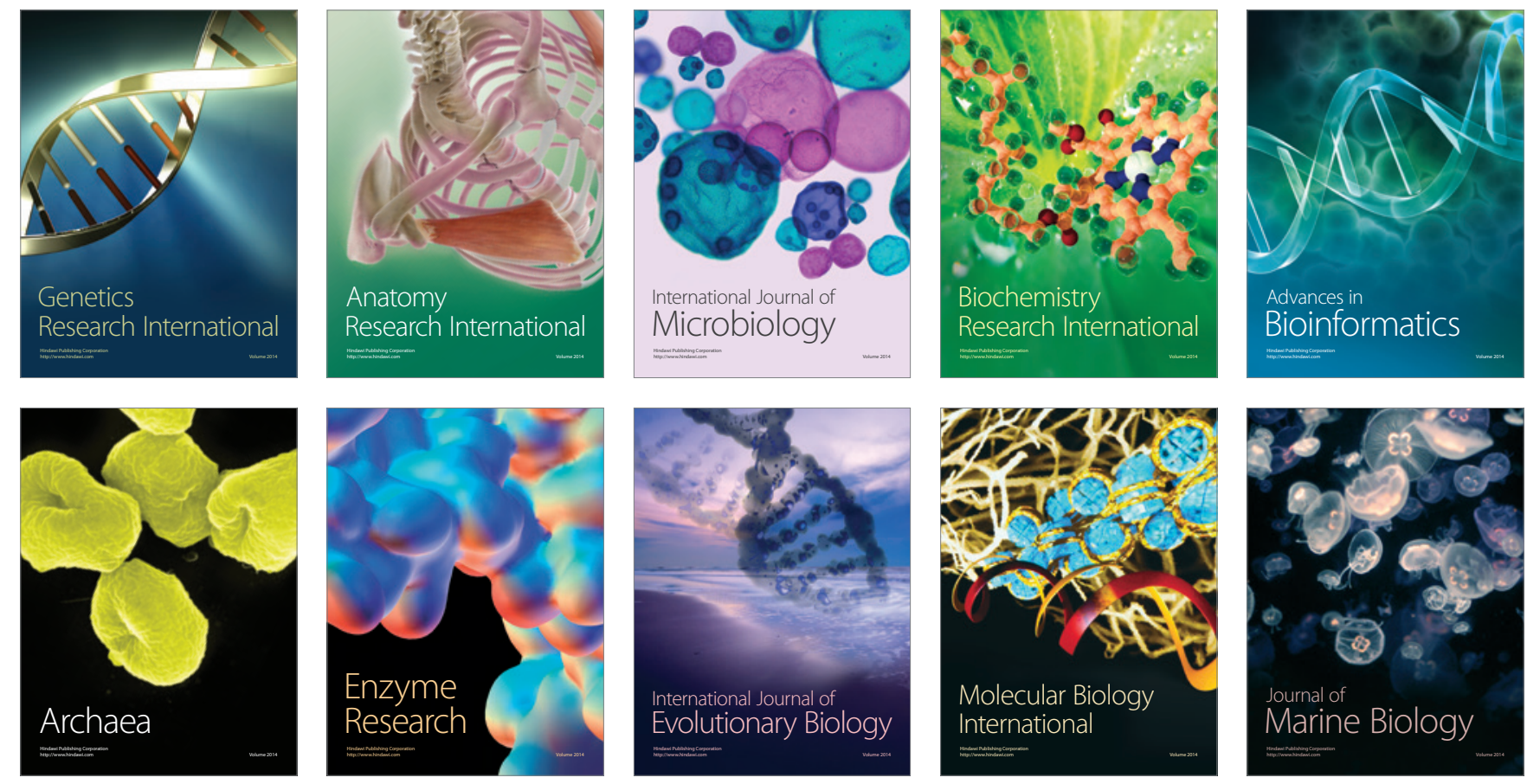